\title{
Integrated patient records: another move towards quality for patients?
}

At a time when the health service is becoming aware of patients as the focus of its activity, ${ }^{1-3}$ the organisation and structure of records have not developed to reflect this consciousness. Notes of medical care, nursing care, and other care generally remain separate, with a professional or treatment orientation rather than a patient focus. Why is the shift towards multidisciplinary, patient focused care not yet supported by integrated records which record information round the patient, ${ }^{4}$ even though successful operational examples exist? ${ }^{5} 6$

Traditionally, the medical record is episode focused, concentrating on the delivery of care during that episode, which may embrace a discrete illness or part of a period of ill health. It is provider based, not patient based, and during the lifetime of an individual patient it will emerge in many different forms in primary care, community care, and secondary care. Even in secondary care different records will be held by different provider units, and within one unit different records will be generated by doctors, nurses, paramedical professionals, and specialist departments. The patient is disadvantaged because there is no complete record of clinical history or treatment received and because care is given without full knowledge of the patient's history.

The health service reforms, though promoting multidisciplinary working through clinical teams and directorates, may reduce record sharing between care providers. Moreover, the move towards consultant episodes may fragment the record even further. ${ }^{7}$ On the other hand, the development of a consumer oriented society in parallel with the commercialisation of health provision is raising awareness of health matters and strengthening the public sense of responsibility towards health. Thus individuals are encouraged to participate in health promotion and health care planning and provision. If this is to be effective, and if it is to be matched by an equal commitment by professionals to considering the whole person, data on a patient's health and disease need to be held in a record which is individual but composite, relevant, appropriate, and useful to that patient.

\section{Structure of records}

The Tunbridge report on personal health records identified standards for hospital medical records, ${ }^{8}$ but the Department of Health offers no guidance as to the precise details which doctors or other health professionals should include in the records they keep, with the exception of midwives for whom record keeping is a statutory requirement in their practice. The King's Fund identified that the main purposes of the nursing record are to demonstrate that nursing care is planned and is not simply a haphazard series of events or tasks; to demonstrate that each patient appears to receive the appropriate nursing care at a professionally acceptable standard; to maintain continuity and provide a means of communication between nurses and other relevant disciplines; to record any changes in the condition or circumstances of the patient; and to provide a permanent record for future reference for research, teaching or investigation for legal purposes, or both. ${ }^{9}$ Recently, more comprehensive standards for nursing records and record keeping have been set by the United Kingdom Central Council for Nursing, Midwifery, and Health Visiting. ${ }^{10}$ Against this background, what is recorded, by whom, and with what frequency is a matter for professional judgement in the light of local practice.

No such guidelines exist for doctors about the content of the medical record, but the quality of medical records has been widely criticised and is suggested as the main target for audit by the Royal College of Physicians. ${ }^{11}$ The quality of communication between primary and secondary care is a recurring cause for concern. ${ }^{12-14}$

An adequately summarised patient record on paper is a prerequisite for the successful transfer of information. Kay et al maintain that the current organisation, style, and layout of medical records convey details often not expressed directly in the content. The solution is not necessarily an electronic record, in which much of the content and value are lost. ${ }^{15}$ Kay et al emphasise the need for a structured framework to improve the current manual record, not impoverish it, as well as to stimulate the effective development of electronic medical records in due course.

Currently, most data collected in the medical record provide activity or process oriented information, rather than data on objectives or patient related outcome. Little care is taken to record carefully the clinical state of the patient at intervals during the illness, so that accurate monitoring of progress is difficult. Similarly, the medical record concentrates little on care planning, though this is a greater feature of the records of nursing and other professions.

Weed considered the patient's record to be the "tool" which facilitates the accomplishment of goals set for and with the patient. ${ }^{16} \mathrm{He}$ emphasised that all members of the health care team should contribute to the record, with the organisational basis being the patient, and identified four basic phases of activity: establishing a database; forming a problem list; preparing an initial plan for each problem; and maintaining progress notes on each problem. However, the concept has not been widely adopted, perhaps because of the use of the term "problem orientated medical record" rather than "problem oriented patient record."

\section{Benefits of integrated records}

Integration of the records means integration of the methods of working of all involved: doctors, nurses, paramedical professionals, and patient. It implies the necessity for collaboration in patient assessment, planning of care, and identification of outcomes. The collaborative care planning pilot study in the west midlands identified the benefits to the patient as being improved quality of care through patient involvement in planning of care, better patient education, improved 
admission procedures, improved discharge procedures by early planning, and more staff time with patients. ${ }^{17}$ There would also be benefits to the health professionals and their parent organisations, improving communication, reducing duplicate data collection, and promoting more efficient working. Above all, sharing of records of the progress of care and of the patient's response are self evident in improving the quality of that care.

Placing the patient as a focus for setting outcome standards would, in due course, enable audit of patient focused care. ${ }^{18}$ Audit should be a mechanism for ensuring a people centred approach to examining the patient's experience and improving it, when appropriate, as well as contributing to an improvement in the health status of the patient, taking into account physical, psychological, emotional, and social factors. Involving the patient in these issues would benefit most patients individually and society in general through better understanding of needs, outcomes, and priorities.

The concept of outcome measurement means different things to different people ${ }^{19}$; clinicians are concerned with the direct results of interventions with individual patients whereas managers are concerned with resource utilisation to provide effective and efficient services. The prime concern of patients is usually to seek a cure or at least relief of distress, discomfort, or disability, though other factors such as access to services, choice, safety, and value for money may play a part. Above all, patients wish to be treated as people rather than as cases, diagnoses, or statistics.

\section{Issues for resolution}

If the arguments for integrated records are accepted, many issues emerge for debate: whether integrated working or integrated records comes first; whether integrated records will catalyse the organisational development required or emerge only as a result of it; how far such records should extend; whether they should embrace just clinical teams or whole hospitals, or even hospitals and communities; whether perhaps they should be nationwide. Whatever the scope of the record, considerable attitudinal and organisational change will be required. How to achieve a common understanding of responsibilities, a common language, and common methods of recording are further questions. We have already drawn attention to the need to address the language of the dynamics of care (M J Rigby et al, personal communication), in parallel with the development of a thesaurus of clinical terms which will result from the clinical terms project. ${ }^{20}$

There are ethical and managerial issues also to be addressed if integrated patient records are to comprise a complete health and illness history. These include who will own and who will manage the integrated record, who will be allowed to enter which facts and opinions, and what rules will govern levels of access and confidentiality of data. If the record is truly patient focused, consideration must be given to allowing recording of data directly by the patient or through the proxy of a carer; the control the patient will have over what data are included and what are excluded; and whether the record contains information about the informal carers, including their abilities and difficulties, and what rights they have as data subjects. Other important issues are whether the record will travel between provider settings or be accessible to other providers; whether managerial and organisational data will be included; and whether such records cost more. These issues must be faced if good quality patient based care is to be achieved. They may appear as obstacles to the professions, but they are the key to enablement for patients.

The goal of seamless care, ${ }^{21}$ with diverse disciplines focusing on optimum, efficient, and effective health care delivery to each and every patient implies a seamless patient record. We have yet to prove that the seams are not the most enduring as well as the most uncomfortable part of the garment, and there is a long way to go before they are no longer visible.

J G WILLIAMS

Director,

School of Postgraduate Studies in Medical and Health Care,

Maes y Gwernen Hall,

Morriston Hospital,

Swansea SA6 6NL

R ROBERTS

All Wales Nursing Information Systems Project Manager,

Welsh Health Common Services Authority Information Group,

Computer Centre,

Cardiff CF4 $7 X^{\mathcal{F}}$

M J RIGBY

Lecturer,

Centre for Health Planning and Management,

Keele University,

Keele,

Staffordshire ST5 5SP

1 Secretaries of State for Health, Wales, Northern Ireland, and Scotland. Medical audit. Working paper 6. London: HMSO, 1989.

Secretaries of State for Health, Wales, Northern Ireland, and Scotland. Education and training. Working paper 10. London: HMSO, 1989.

Secretary of State for Health. The health of the nation: a strategy for health in England. London: HMSO, 1992:124-6. (Cm 1986.)

4 Rigby MJ. Recording information round the patient-moving towards a vision. In: Lun KC, Degoulet P, Peimme TE, Reinhoff E. Proceedings of the seventh World Congress on Medical Informatics. Amsterdam Elsevier Science Publications, 1992:716-21.

5 Rigby MJ. An electronic patient information system in mental health an integrated solution for better care and management. In: Adlassnig K-P, Grabner G, Bergtsson S, Hansen R, eds. Medical informatics Europe 1991 proceedings. Berlin: Springer-Verlag, 1991:722-6.

6 Rigby MJ, Robins SC. Connection machine. British Yournal of Healthcare Computing 1992;9:9-10.

7 Clark A, McKee M. The consultant episode: an unhelpful measure. BMF 1992;305:1307-8.

8 Ministry of Health Central Health Services Council. Standardisation of hospital medical records. Report of the Subcommittee of the Standing Medical Advisory Committee. London: HMSO, 1965. (Tunbridge Report.)

9 King's Fund. $A$ handbook for nurse to nurse reporting. London: King's Fund, 1983. (Project paper No 21.)

10 United Kingdom Central Council for Nursing, Midwifery, and Health Visiting. Standards for records and record keeping. London: UKCC, 1993.

11 Royal College of Physicians of London. Medical audit: a first report. Why, what and how? London: Royal College of Physicians of London, 1989 .

12 Penny TM. Delayed communication between hospitals and general practitioners: where does the problem lie? $B M F$ 1988;297:28-9.

13 Williams IE, Fitton F. Factors affecting early unplanned readmission of elderly patients to hospital. $B M \mathcal{F} 1988 ; 297: 784-7$.

14 King N, Coventry P. Past imperfect, future tense. Health Services fournal 1992;102(2):24-5.

15 Kay S, Rector AL, Nowlan WA, Goble CA, Horlan B, Howkins TJ, et al. What should we mean by an electronic medical record? In: Adlassnig K-P, Grabner G, Bergtsson S, Hansen R, eds. Medical Adlassnig K-P, Grabner G, Bergtsson S, Hansen R, eds. Medical informatics

16 Weed LL. Medical records, medical education and patient care: the problemoriented record as a basic tool. Cleveland, Ohio: Case Western Reserve University Press, 1969.

17 Finnegan E. Collaborative care planning. A natural catalyst for change. Birmingham: West Midlands Health Region Resource Management Support Unit, 1991 .

18 Bardsley MJ, Cole JM. Practical experiences in auditing patient outcomes. Quality in Health Care 1992;1:124-30.

19 Austin C, Clark C. Measures of outcome: for whom? British fournal of Occupational Therapy 1993;56:21-4.

20 Buckland R. The language of health. BMF 1993;306:287-8.

21 Nichol D. Vision vs reality. British Fournal of Healthcare Computing 1992;9:8-9. 